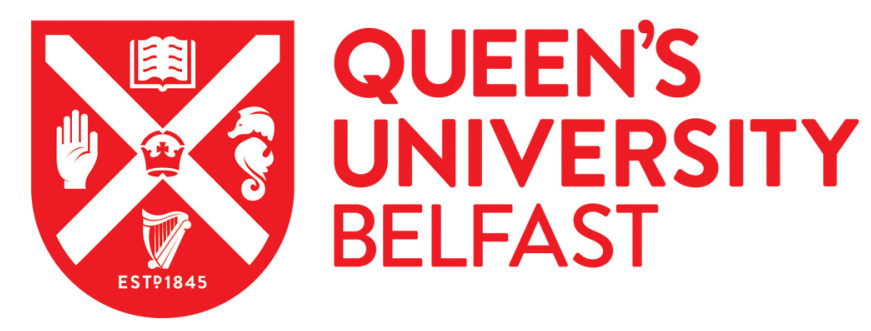

\title{
Water depth-dependent notonectid predatory impacts across larval mosquito ontogeny
}

Dalal, A., Cuthbert, R. N., Dick, J. T. A., \& Gupta, S. (2019). Water depth-dependent notonectid predatory impacts across larval mosquito ontogeny. Pest Management Science. https://doi.org/10.1002/ps.5368

\author{
Published in: \\ Pest Management Science
}

Document Version:

Peer reviewed version

Queen's University Belfast - Research Portal:

Link to publication record in Queen's University Belfast Research Portal

Publisher rights

(C) 2019 Society of Chemical Industry.

This work is made available online in accordance with the publisher's policies. Please refer to any applicable terms of use of the publisher.

\section{General rights}

Copyright for the publications made accessible via the Queen's University Belfast Research Portal is retained by the author(s) and / or other copyright owners and it is a condition of accessing these publications that users recognise and abide by the legal requirements associated with these rights.

Take down policy

The Research Portal is Queen's institutional repository that provides access to Queen's research output. Every effort has been made to ensure that content in the Research Portal does not infringe any person's rights, or applicable UK laws. If you discover content in the Research Portal that you believe breaches copyright or violates any law, please contact openaccess@qub.ac.uk. 


\title{
Water depth-dependent notonectid predatory impacts across larval mosquito ontogeny
}

A short running title: Notonectid predation against mosquito larvae Arpita Dalal* ${ }^{1}$, Ross N. Cuthbert ${ }^{2}$, Jaimie T.A. Dick ${ }^{2}$ and Susmita Gupta ${ }^{1}$

${ }^{1}$ Department of Ecology and Environmental Science, Assam University, Silchar- 788011, India ${ }^{2}$ Institute for Global Food Security, School of Biological Sciences, Queen's University Belfast, Medical Biology Centre, 97 Lisburn Road, Belfast BT9 7BL, Northern Ireland, United Kingdom

*Correspondence to: Arpita Dalal, Department of Ecology and Environmental Science, Assam University, Silchar, India, Email: rptdl14@gmail.com

\begin{abstract}
BACKGROUND: Context-dependencies can modulate the strength of predatory interactions and often remain unquantified. In particular, differences in water depth within aquatic systems could influence predator efficiencies towards prey which utilise 3D-space through the water column. Differences in prey size could drive prey size-refuge effects, influencing the efficacy of natural enemies towards vector species. We thus quantify the predatory impact of two notonectid predators, Anisops breddini and Anisops sardeus, towards four different larval instars of Culex quinquefasciatus prey across a water depth gradient, using functional responses (FRs).

RESULTS: Consumption rates differed significantly between the predators, and interspecific differences in responses to variations in water depth were emergent. Both notonectids were able to handle $C$. quinquefasciatus prey across all instar stages, yet predation rates were generally
\end{abstract} This article has been accepted for publication and undergone full peer review but has not been through the copyediting, typesetting, pagination and proofreading process, which may lead to differences between this version and the Version of Record. Please cite this article as doi: 10.1002/ps.5368 
higher towards early as opposed to late instar prey. Anisops sardeus was most voracious, and differential predation rates of this species were most pronounced in shallow waters. Type II FRs were displayed by notonectids in the majority of treatments; however, Type III FRs were emergent in specific treatment groups, with potential implications for prey population stability. Both capture rates and handling times were often greater at greater depths, and thus maximum feeding rates reduced as depth increased. Our results further demonstrate substantial predatory impacts of notonectid predators towards mosquito, and quantify biotic and abiotic contextdependencies which modulate their impact.

CONCLUSION: Given notonectids are capable of aerial dispersal between ephemeral aquatic habitats of varied volumes, their promotion in aquatic systems could help reduce proliferations of medically important mosquitoes.

Keywords: functional response, Culex quiquefasciatus, biological control, water depth, prey size

\section{INTRODUCTION}

Predator communities play a crucial role in the regulation of prey populations in natural systems, ${ }^{1,2}$ which, in turn, influences structuring and functioning at the ecosystem level. ${ }^{3,4}$ In ephemeral aquatic ecosystems especially, predaceous insects such as hemipterans, coleopteran larvae and odonate larvae are often top predators, ${ }^{5}$ and have the potential to structure communities via trait- and density-mediated interactions with their prey. ${ }^{6,7}$ However, both biotic and abiotic context dependencies can alter interaction strengths between trophic groups in aquatic ecosystems, and predictive understandings of how such contexts influence crucial topdown processes such as predation are lacking. In particular, within a biological control context, 
environmental contexts could have important consequences for target prey population regulation, including towards medically important vector species.

Mosquitoes are vectors of deadly human diseases such as malaria, dengue, Zika, and yellow fever, especially in the tropics, with more than one billion people infected and over 700,000 people dying from vector-borne diseases annually. ${ }^{8}$ Mosquitoes successfully colonise a vast range of natural and artificial aquatic systems, including in urban areas where there is a high potential for encounters with humans. ${ }^{9}$ In particular, Culex quinquefasciatus Say, 1823 (Diptera: Culicidae) is a member of Culex pipiens complex and is a competent vector of brancroftian filariasis, West Nile virus, Sandbis virus, St Louis encephalitis, Rift Valley fever virus and lymphatic filariasis (see ${ }^{10,11,12}$ ). Mosquitoes in the C. pipiens complex exhibit an abundant and worldwide distribution, and are known to colonise a broad range of aquatic environments, including wetlands, rice fields and artificial containers. ${ }^{13,14,15}$ To combat these vectors, predators such as aquatic insects, arachnids, crustaceans, fish, birds and bats have been identified. ${ }^{16,17,18}$ Biological control using predators has been effective in mosquito population management strategies (e.g. ${ }^{19}$ ), and particularly during efforts which target mosquitoes during their aquatic larval life history stage. However, context-dependencies, such as changes in water depth or mosquito prey size, could exert a significant influence on the efficacy of biocontrol agents, and should thus be integrated into considerations among candidate natural enemies.

Functional responses (FRs) are central to the derivation of density-dependent consumerresource (e.g. predator-prey) interaction strengths. ${ }^{20,21}$ The capture rate (i.e. attack rate, search efficiency), handling time and maximum feeding rate parameters are central components of FRs, and have been shown to be congruent with ecological impacts in biological control agent examinations. ${ }^{17,18,22}$ Indeed, comparative FRs can be integrated to examine relative efficacies 
between biological control agents in vector control, and across multiple environmental contexts. ${ }^{17,18}$ Three form of FRs types (shapes) have been described: Type I, II and III. ${ }^{20,23,24}$ In a predatory biocontrol context, the identification of agents which exhibit Type II FRs is desirable due to their potentially population destabilising effects, attributable to high rates of prey consumption at low densities that reduces the potential for prey refuge and thus persistence. ${ }^{25}$ In the context of mosquitoes, Type II FRs may reduce the recruitment of mosquitoes through to the adult stage that is capable of vectoring disease. In contrast to Type II FRs, Type III FRs may impart stability to prey populations by providing refugia to low prey densities, owing to low proportional consumption rates where prey are scarce. ${ }^{20}$

Notonectids (water boatmen) are voracious predators and are known to play a key role in the structuring of aquatic communities (e.g. ${ }^{26,27}$ ). In the tropics, this group is often dominant in both natural and artificial ephemeral aquatic ecosystems, where mosquitoes successfully establish. ${ }^{28,29}$ Whilst their diet is known to include all size classes of mosquito larvae, efficiencies can vary substantially according to the larval ontogenic stage of mosquito prey. ${ }^{30}$ Although predatory efficacy of notonectids towards mosquito larvae has been well-described (e.g. ${ }^{31,32,33}$ ), it is unclear how variabilities in search area within 3D aquatic ecosystems influences the strength of offtake rates by such consumers. This is particularly important for mosquito prey, which forage throughout the water column. Indeed, examinations of biotic interactions often fail to address potential water depth variations, despite the dynamic and transient nature of small aquatic habitats where mosquitoes breed. Therefore, the present study employs comparative FRs (e.g. ${ }^{17,18,27,34}$ ) to decipher the effects of water depth on the predatory impact of two widespread and abundant notonectid predators, Anisops breddini Kirkaldy, 1901 
(Heteroptera: Notonectidae) and Anisops sardeus Herrich-Schaeffer, 1849 (Heteroptera:

Notonectidae) towards four larval instar stages of Culex quiquefasciatus prey.

\section{MATERIALS AND METHODS}

\subsection{Collection of predators and prey}

The focal predators, size-matched adult A. breddini $(7.04 \pm 0.06 \mathrm{~mm})$ and A. sardeus

(7.21 $\pm 0.06 \mathrm{~mm}$ ) were collected from fishery ponds (pond 1: 3800 sq. $\mathrm{m}, \sim 70 \mathrm{~cm}$ depth; pond 2 :

3100 sq. $\mathrm{m}, \sim 62 \mathrm{~cm}$ depth) of Irongmara, Cachar, Assam, India $\left(24^{\circ} 41^{\prime} 15.78^{\prime \prime} \mathrm{N}, 92^{\circ} 45^{\prime} 12.21 " \mathrm{E}\right)$

during the 2017 summer-monsoon season by trawling a kick net through the water column by hand. These notonectids were transported in source water to a laboratory in the Department of Ecology and Environmental Science, Assam University, Silchar. Both species were kept separately in a glass aquaria holding $25 \mathrm{~L}$ de-chlorinated tap water with continuous aeration. The laboratory was maintained at $30{ }^{\circ} \mathrm{C}\left( \pm 2{ }^{\circ} \mathrm{C}\right)$ on a $12: 12$ light:dark photoperiod, and notonectids were acclimated to these conditions for at least one week prior to the experiment, with water changed every 10 days and fed ad libitum with mosquito and chironomid larvae.

The prey, larvae of $C$. quinquefasciatus, were collected from the Assam University campus by sampling egg rafts from artificial container that were filled with jaggery and water mixture to attract oviposition. The mosquito egg rafts were then transferred to the same laboratory as the notonectids, where, upon hatching, mosquito larvae were reared to the desired size class on a diet of crushed jaggery (Arya Farm Products Pvt. Ltd) ad libitum. Jaggery is a traditional non-centrifugal organic cane sugar lump made from date or palm tree.

\subsection{Functional response experiment}


Individuals of each predator species were starved in isolation for $24 \mathrm{~h}$ prior to experimentation to standardize hunger levels. We employed a factorial ' $3 \times 2 \times 4 \times 6$ ' experimental design to discern the effects of 'water depth', 'predator species', 'prey instar' and 'prey density', respectively, on notonectid-mosquito interaction strengths. Feeding trials were conducted in glass aquaria with a standard surface area of $18 \mathrm{~cm}^{2}$. Aquaria were filled with dechlorinated tap water to three different depths: $5 \mathrm{~cm}(\mathrm{D} 1, \sim 1.44 \mathrm{~L}), 10 \mathrm{~cm}(\mathrm{D} 2, \sim 2.95 \mathrm{~L})$ and 15 cm (D3, 4.45 L). Both predator species (A. breddini and A. sardeus) were separately provided four different instar stages of $C$. quinquefasciatus (i.e. $1^{\text {st }}$ instar, $1.1 \pm 0.02 \mathrm{~mm} ; 2^{\text {nd }}$ instar, $2.21 \pm$ $0.05 \mathrm{~mm} ; 3^{\text {rd }}$ instar, $3.99 \pm 0.03 \mathrm{~mm} ; 4^{\text {th }}$ instar, $\left.4.9 \pm 0.05 \mathrm{~mm}\right)$ under six prey densities $(5,10$, $25,50,75,100 ; n=3$ per experimental group). Following the addition of prey, notonectids were introduced to individual arenas and were allowed to feed for $24 \mathrm{~h}$, after which the predators were removed and numbers of remaining live prey enumerated to quantify numbers killed. To eliminate time confounds, batches of experimental trials were fully randomised according to experimental treatment groups. Controls consisted of prey without predators at each water depth, prey instar stage and prey density ( $n=3$ per experimental group).

Statistical analyses were performed in R v3.3.2. ${ }^{35}$ Raw consumption was analysed with respect to 'water depth', 'predator species' and 'prey instar', and their interactions, using generalised linear model (GLM) assuming a quasi-Poisson family, owing to residual overdispersion. 'Prey density' was included as an individual effect, owing to its importance in FR derivations. F-tests with Type III sums of squares were employed to derive main effects. Post hoc Tukey tests were conducted for pairwise comparisons of significant effects. ${ }^{36}$

To discern FR types, logistic regression of the proportion of prey killed as a function of prey density was used for across each experimental group. ${ }^{24,35,37}$ Here, a significantly negative 
first order term indicates a Type II FR, whilst a significantly positive first order term followed by a significantly negative second order term indicates a Type III FR. A generalised form of the FR was implemented that accounts for non-replacement of prey (i.e. prey depletion) over the allocated experimental time: ${ }^{37,38,39}$

$$
N_{e}=N_{0}\left(1-\exp \left(b N_{0}^{q}\left(h N_{e}-T\right)\right)\right)
$$

where $b$ is the attack or capture rate, which, combined with the scaling exponent $q$, gives the density-dependent capture rate $\left(b N_{0}^{q}\right), h$ is the handling time, $T$ is the total experimental time, $N_{0}$ is the initial prey density and $N_{e}$ is the number of prey eaten. Here, $q$ can be fixed at 0 (a Type II FR), 1 (a Type III FR) or instead optimized, providing a means to examine fits of categorical (i.e. Type II or III) or continuous (i.e. flexible) forms. We used maximum likelihood estimation for model fitting. ${ }^{40}$ Where FR types were equivocal, we compared candidate models using Akaike's Information Criterion and fit models which minimised information loss (AIC; lower values indicate better fit). We then non-parametrically bootstrapped starting FR fits $(n=2000)$ to produce $95 \%$ confidence intervals (CIs) around FRs for each predator treatment combination, where significant differences were then deduced on the basis of CI overlaps.

\section{RESULTS}

Survival of prey was $100 \%$ in the control groups across all treatments, and experimental mortality was thus attributed to predation by notonectids. Overall, consumption of $C$. quinquefasciatus larvae was not significantly affected by water depth $\left(F_{2,403}=1.391, P=0.250\right)$. Anisops sardeus consumed significantly more prey than did A. breddini overall $\left(F_{1,403}=16.516\right.$, $P<0.001 ;$ Fig. 1). There were significant consumptive differences between prey instar stages by 
notonectids $\left(F_{3,403}=138.336, P<0.001 ;\right.$ Fig. 1$)$. Significantly fewer $4^{\text {th }}$ instar mosquito prey were consumed than earlier instars (all $P<0.001$ ), whilst $2^{\text {nd }}$ instar prey were consumed most (all $P<0.001)$. In turn, $3^{\text {rd }}$ instar prey were consumed less than $1^{\text {st }}$ instars overall $(P=0.010)$. However, the differential consumption of prey across instar stages was significantly altered by variations in water depth $\left(F_{3,403}=3.044, P=0.006\right.$; Fig. 1$)$. Here, the effects of water depth were most pronounced for consumption of $1^{\text {st }}$ instar prey, with significantly more prey killed at low and intermediate depths as compared to the greatest depth (both $P<0.001$ ). Conversely, for $2^{\text {nd }}-4^{\text {th }}$ instars prey, there were no overall significant consumptive differences across each water depth level (all $P>0.05$ ). However, A significant 'water depth $\times$ predator species $\times$ prey instar' interaction term further indicated emergent complexities in feeding patterns between experimental treatments $\left(F_{6,403}=4.802, P<0.001\right)$. Here, consumption by $A$. sardeus towards $1^{\text {st }}$ instar prey was most affected by water depth variations, and highest at intermediate depths as compared to either low or high depths (both $P<0.01$; Fig. 1e). On the other hand, consumption by $A$. breddini was significantly greater at the lowest depth towards $1^{\text {st }}$ instar prey, as compared to intermediate and high depths (both $\mathrm{P}<0.05$; Fig. 1a). Consumption of $2^{\text {nd }}$ instar prey by $A$. breddini was, however, significantly greater at the intermediate as oppose to the low water depth $(P<0.05$; Fig. 1b). Furthermore, significantly more prey were consumed as higher densities of prey were supplied overall $\left(F_{5,403}=317.798, P<0.001\right)$.

Type II FRs were most prevalent across experimental treatment groups, as indicated by significantly negative first order terms (Table 1). However, Type III FRs were evidenced towards $1^{\text {st }}$ and $3^{\text {rd }}$ instar prey at the shallowest depth by $A$. breddini, and towards $2^{\text {nd }}$ instar prey at the greatest depth (Table 1; Fig. 2). Type III FRs were only evidenced at the intermediate depth towards $1^{\text {st }}$ instar prey by $A$. sardeus (Table 1; Fig. 2). For A. breddini, capture rates were 
significantly lower towards $1^{\text {st }}$ instar prey at low water depths (Tab1e 2; Fig 3a). Conversely, towards $2^{\text {nd }}$ instars, $A$. breddini capture rates were significantly reduced at the high depth treatment as compared to low and intermediate groups (Table 2; Fig. 3b). For $3^{\text {rd }}$ instar prey, capture rates increased with greater water depths, with rates significantly reduced at low water depths compared to intermediate and high groups (Table 2; Fig. 3c). Capture rates towards $4^{\text {th }}$ instar prey groups were more similar (Table 2; Fig. 3d). Overall, A. breddini capture rates were relatively similar among instar stages (Fig. 3a-d).

For A. sardeus, capture rates were significantly lower towards $1^{\text {st }}$ instar prey at intermediate water depths, as compared to low and high depths (Table 2; Fig. 3e). In turn, capture rates were significantly greater at the high compared to low depth here (Table 2; Fig. 3e). However, towards $2^{\text {nd }}$ instar prey, capture rates were generally low and relatively unaffected by variations in water depth (Table 2; Fig. 3f). Capture rates of $3^{\text {rd }}$ instar prey by A. sardeus were significantly reduced in the deepest treatment group, yet were more similar between intermediate and low depths (Table 2; Fig. 3g). Capture rates towards $4^{\text {th }}$ instar prey were significantly reduced at the low as compared to intermediate and high depths (Table 2; Fig. 3h), and were significantly higher than towards all other prey instars (Fig. 3e-h). Capture rates of A. sardeus tended to be higher than $A$ breddini overall towards towards $1^{\text {st }}, 3^{\text {rd }}$ and $4^{\text {th }}$ instar $C$. quinquefasciatus prey, whilst they were reduced toward $2^{\text {nd }}$ instar groups (Fig. 3).

Overall, for $A$. breddini, handling times were similar across water depths for $1^{\text {st }}, 2^{\text {nd }}$ and $3^{\text {rd }}$ instar prey, owing to overlapping of CIs (Fig. $4 \mathrm{a}-\mathrm{c}$ ). However, for these prey groups, handling times tended to be lowest at intermediate water depths (Table 2). For A. breddini, $4^{\text {th }}$ instar handling times were also not significantly different according to water depth (Fig. 4d), yet tended to be reduced at low depths (Table 2). Overall, $4^{\text {th }}$ instar prey handling times were 
significantly longer than most other prey groups (Table 2; Fig. 4a-d). Accordingly, FR magnitudes were significantly reduced for this prey stage (Fig. 2a-d).

For A. sardeus, handling times were significantly shorter at the low and intermediate depths towards $1^{\text {st }}$ instar prey, as compared to the high depth (Table 2; Fig. 4e). Towards $2^{\text {nd }}$ instar prey, handling times were similar at intermediate and high depths (Table 2; Fig. 4f), but were significantly shorter at low compared to intermediate depths. For $3^{\text {rd }}$ instar prey, handling times by $A$. sardeus were not significantly different across water depths (Fig. 4g), however were generally reduced at the highest depth treatment (Table 2). Handling times for $4^{\text {th }}$ instar prey were not significantly different across depth treatments (Table 2; Fig. 4h), however $4^{\text {th }}$ instar prey handling times were significantly greater than all other prey types (Fig. 4e-h). Functional response magnitudes were thus significantly reduced for $4^{\text {th }}$ instar prey (Fig. 2e-h). Handling times of $C$. quinquefasciatus prey were generally similar between the two predators overall (Fig. 4).

\section{DISCUSSION}

Biological control of mosquitoes using natural enemies can be effective to mitigate the proliferation and emergence of medically important mosquito species (e.g. ${ }^{19,41}$ ). However, the impacts of predators on prey have been shown to be highly context-dependent, with both biotic

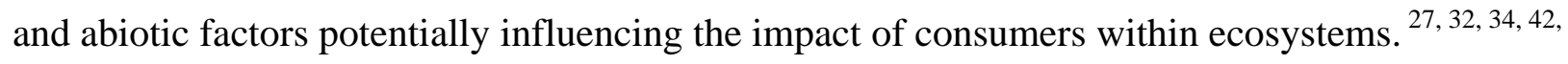
${ }^{43}$ In this regard, FRs can act as a framework in deciphering the predatory potential of biological control agents in controlling larval disease vectors in aquatic ecosystems. ${ }^{17,18,32,34,43}$ During the present study, A. sardeus was identified as a more voracious predator than A. breddini. Whilst potentially destabilising Type II FRs were most prevalent between the predators, the present 
study also found emergent evidence for Type III FRs congruent with prey population stabilizing effects. Although interactive complexities were present in our results between water depths, predator species and prey sizes, consumptive differences between depths were particularly marked towards early mosquito instars, wherein predators consumed less in deeper waters. Moreover, earlier instar prey tended to be impacted more greatly than late instar mosquitoes, with handling times longer and thus maximum feeding rates lower for these groups. Second instar prey were most consumed overall.

Within laboratory settings, predator-prey interactions with invertebrate consumers typically conform to Type II FRs (e.g. ${ }^{32,33,43}$ ). In the present study, although both of the focal notonectids displayed Type II and Type III FRs, A. sardeus mostly showed Type II FRs, indicating that population-destabilising predatory impacts from this species upon low densities of mosquito larvae are particularly high, and robust to variations in water depth and prey size. The selection of biological control agents which are able to handle larval mosquitoes throughout their ontogeny is beneficial, given that size refuge effects in large mosquito prey could facilitate competition alleviation, in turn producing larger adults and that are better vectors. ${ }^{44}$ Thus, the present study identifies notonectids as effective mosquito predators, and particularly A. sardeus which exhibits higher capture rates towards late instar prey, and so minimizes refuge effects. ${ }^{25,34}$ Indeed, many predators are unable to handle resources relatively big or small, potentially reducing population-level offtake rates. ${ }^{45,46}$ However, further research is required to quantify selectivity traits between multiple coexisting mosquito size classes. In contrast to Type II FRs, Type III FRs could have stabilising effects on prey that are associated with low-density prey refugia. ${ }^{25,47}$ Therefore, whilst predation by $A$. sardeus has the potential for high impact on mosquito prey at low densities, A. breddini on the other hand, may better allow mosquito larvae 
to persist via low density refugia in container-style habitats for specific water depths and prey sizes. However, empirically, Type III FRs could also be intertwined with switching behaviours, where the predator encounters alternative prey and exhibits frequency-dependent predation strategies $\left(\right.$ see $\left.^{48}\right)$. Although, studies have repeatedly found notonectids to preferentially select mosquito prey, which may minimize such effects although; yet, this was not assessed in the present study. $49,50,51,52$

In many cases, capture rates of $A$. sardeus surpassed those of $A$. breddini. The higher capture rates of $A$. sardeus compared to A. breddini further indicate higher predation pressure on mosquito larvae by this species at low prey densities. Capture rates of $A$. breddini were highest for $2^{\text {nd }}$ followed by $3^{\text {rd }}$ instars of mosquito prey. This suggests a unimodal response of capture rates to prey sizes, whilst handling time were generally shorter for small-sized prey, indicating greater maximum feeding rates. This result is consistent with previous work on other notonectids which displayed similar consumptive traits $\left(\right.$ see $\left.^{30}\right)$. According to the optimal foraging theory, prey of intermediate relative size (i.e. $2^{\text {nd }}$ and $3^{\text {rd }}$ instars of mosquito larvae) are considered to be the most profitable prey for predators. ${ }^{53}$ Given capture rates by A. breddini were greater mostly in higher water depths, destabilizing predatory impact on low prey densities can be deemed most profound in these water depths. On the other hand, handling times of A. breddini were typically longest in the lowest water depth and for the largest prey, indicating maximum feeding rates were generally decreased by reductions in water depth and greater prey size. For A. sardeus, capture rates were also mostly elevated in deeper waters, whilst, conversely, handling times were often reduced in shallow water. Further, both capture rates and handling times of $A$. sardeus generally increased with increasing prey size. This result corroborates with other predatory aquatic insects, such as odonates, belosomatids and other species of notonectids, which display 
higher attack rates and handling times for larger instar stages of mosquito larvae. ${ }^{54,55}$ This might be due to the increasing ability of the predator to detect larger prey, coupled with a longer time to subdue and consume such prey items (see ${ }^{56}$ ). Given both predators capture their prey by ambush, greater search areas may enhance capture efficiencies. Thus, the overall predatory impact of $A$. breddini and A. sardeus were dependent both on physical (water depth) and biotic (prey size and densities) factors.

Our findings corroborate with the results of previous work where notonectid predators were identified as potential biocontrol agents for mosquito larvae under laboratory conditions. ${ }^{32}$, $33,54,57,58$ Similar to our findings, the rate of consumption of mosquito larvae by a congeneric species of Anisops were higher in lower volumes of water. ${ }^{32}$ Previous studies have also shown that notonectid predators preferentially consume mosquito larvae over other alternative prey (e.g. $49,50,51,52)$. This further demonstrates the biocontrol efficacy of notonectid predators in controlling mosquito larvae in a container style habitat with multiple prey types. Considering the depth of water used in the present study experiment, notonectids may be effectively used in small natural or artificial aquatic bodies where mosquitoes successfully colonise. Unlike many other natural enemies of mosquitoes, notonectids carry an air bubble (atmospheric oxygen) on their abdomen, allowing them to be less susceptible to poor water qualities than other groups. ${ }^{59}$ In particular, in the urban environment where aquatic systems are often highly polluted, notonectids are able to aerially colonise aquatic systems where other predators cannot persist. ${ }^{60}$ Although the presence of notonectids in aquatic systems can lead to oviposition avoidance by mosquitoes, arrival of these predators after oviposition events via aerial dispersal could enable efficacious mosquito control across landscapes. ${ }^{61}$ Furthermore, Anisopinae (sub-family of Notonectidae) species can remain under water for much longer durations than Notonectinae sub-family species 
as they can attain neutral buoyancy at water depth. ${ }^{59}$ Therefore, given out results, both $A$. breddini and A. sardeus, have the potential to efficiently reduce populations of mosquitoes across varying levels of prey ontogeny, water depth and prey density. Further field studies and research are, however, required to further quantify the roles of notonectids and other invertebrate predators in regulating medically important mosquito species within aquatic habitats.

\section{ACKNOWLEDGEMENTS}

We are grateful to the Dept. of Ecology and Environmental Science, Assam University, Silchar for providing laboratory facilities. We also thank the Department of Science and Technology (DST) for providing financial support through an INSPIRE Fellowship (INSPIRE Fellowship code: IF130185).

\section{REFERENCES}

1 Kerfoot W and Sih A, Predation: Direct and Indirect Impacts on Aquatic Communities. University Press of New England, Hanover (1987).

2 Sih A, Englund G and Wooster D, Emergent impacts of multiple predators on prey. Trends Ecol. Evol. 13: 350-355 (1998).

3 Carpenter SR, Kitchell JF and Hodgson JR, Cascading trophic interactions and lake productivity. Bioscience 35: 634-639 (1985). 
4 Wasserman RJ, Margaux N, Avery TS and Froneman PW, Trophic level stabilityinducing effects of predaceous early juvenile fish in an estuarine mesocosm study. PloS One 8: e61019 (2013).

5 Batzer DP and Wissinger SA, Ecology of insect communities in nontidal wetlands. Annu. Rev. Entomol. 41: 75-100 (1996).

6 Peckarsky BL, Cowan CA, Penton MA and Anderson C, Sublethal consequences of streamdwelling predatory stoneflies on mayfly growth and fecundity. Ecology 74: 1836-1846 (1993). 7 Eubanks MD and Denno RF, Health food versus fast food: the effects of prey quality and mobility on prey selection by a generalist predator and indirect interactions among prey species. Ecol. Entomol. 25: 140-146 (2001).

8 World health organization, Factsheet: Vector borne disease. World health organization (2017).

9 Townroe S and Callaghan A, British container breeding mosquitoes: the impact of urbanisation and climate change on community composition and phenology. PLoS ONE, 9: e95325 (2014). 10 Mandal SK, Ghosh A, Bhattacharjee I and Chandra G, Biocontrol efficiency of odonate nymphs against larvae of the mosquito, Culex quinquefasciatus Say, 1823. Acta Trop 106: 109$114(2008)$

11 Turell MJ, Members of the Culex pipiens complex as vectors of viruses. J Am Mosq Control Assoc 28: 123-126 (2012).

12 Manimegalai $\mathrm{K}$ and Sukanya S, Biology of the filarial vector, Culex quinquefasciatus (Diptera:Culicidae). IJCMAS 3: 718-724 (2014).

13 Miyagi I, Toma T and Mogi M, Biological control of container-breeding mosquitoes, Aedes albopictus and Culex quinquefasciatus, in a Japanese island by release of Toxorhynchites splendens adults. Med Vet Entomol 6: 290-300 (1992). 
14 Jacob BG, Shililu J, Muturi EJ, Mwangangi JM, Muriu SM, Funes J, Githure J, Regens JL and Novak RJ, Spatially targeting Culex quinquefasciatus aquatic habitats on modified land cover for implementing an integrated vector management (IVM) program in three villages within the Mwea Rice Scheme, Kenya. Int. J. Health Geog. 5: 18 (2006).

15 Okiwelu SN and Noutcha MAE, Breeding sites of Culex quinquefasciatus (Say) during the rainy season in rural lowland rainforest, Rivers State, Nigeria. Public Health Research 2: 64-68 (2012).

16 Medlock JM and Snow KR, Natural predators and parasites of British mosquitoes - a review. J Eur Mosq Control Assoc 25: 1-11 (2008).

17 Cuthbert RN, Dick JTA and Callaghan A, Interspecific variation, habitat complexity and ovipositional responses modulate the efficacy of cyclopoid copepods in disease vector control. Biol Control 121: 80-87 (2018a).

18 Cuthbert RN, Dick JTA, Callaghan A and Dickey JWE, Biological control agent selection under environmental change using functional responses, abundances and fecundities; the Relative Control Potential (RCP) metric. Biol Control 121: 50-57 (2018b).

19 Kay BH and Nam VS, New strategy against Aedes aegypti in Vietnam. Lancet 365: 613-617 (2005).

20 Holling CS, Some characteristics of simple types of predation and parasitism. Can Entomol 91: 385-398 (1959).

21 Holling CS, The functional response of invertebrate predators to prey density. Mem. Entomol.

Soc. Can. 48: 1-86 (1966).

22 Van Driesche R and Bellows TS, Biological Control. Springer, Berlin (2011).

23 Taylor RJ, Predation. Chapman and Hall, London (1984). 
24 Juliano SA, Nonlinear curve fitting:predation and functional response curves, in Design and analysis of ecological experiments, ed. by Scheiner SM and Gurevitch J, Oxford University Press, Oxford, pp. 178-196 (2001).

25 Murdoch WW and Oaten A, Predation and population stability. Adv Ecol Res 9: 1-131 (1975).

26 Blaustein L, Influence of the predatory backswimmer, Notonecta maculata, on invertebrate community structure. Ecol. Entomol. 23: 246-252 (1998).

27 Wasserman RJ, Alexander ME, Weyl OLF, Barrios-O’Neill D, Froneman PW and Dalu T, Emergent effects of structural complexity and temperature on predator- prey interactions. Ecosphere 7: e01239 (2016).

28 Das K and Gupta S, Seasonal variation of Hemiptera community of a temple pond of Cachar District, Assam, northeastern India. JoTT 4: 3050-3058 (2012).

29 Dalal A and Gupta S, Aquatic Insects as Pollution Indicator-A Study in Cachar, Assam, Northeast India, in Environmental Pollution, ed. by Singh V, Yadav S and Yadava R, Water Science and Technology Library 77, Springer, Singapore, pp.103-124 (2018).

30 Fischer S, Pereyra D and Fernández L, Predation ability and non-consumptive effects of Notonecta sellata (Heteroptera: Notonectidae) on immature stages of Culex pipiens (Diptera: Culicidae). J Vector Ecol 37: 245-251 (2012).

31 Silberbush A, Tsurim I, Margalith Y and Blaustein L, Interactive effects of salinity and a predator on mosquito oviposition and larval performance. Popul. Ecol. 175: 565-575 (2014). 32 Mondol RP, Chandra G, Bandyopadhyay S and Ghosh A, Effect of temperature and search area on the functional response of Anisops sardea (Hemiptera: Notonectidae) against Anopheles stephensi in laboratory bioassay. Acta Trop 166: 262-267 (2017). 
33 Cuthbert RN, Dalu T, Wasserman RJ, Callaghan A, Weyl OLF and Dick JTA, Using functional responses to quantify notonectid predatory impacts across increasingly complex environments. Acta Oecol (2019). In press. https://doi.org/10.1016/j.actao.2018.11.004

34 Dick JT, Alexander ME, Jeschke JM, Ricciardi A, MacIsaac HJ, Robinson TB, Kumschick S, Weyl OLF, Dunn AM, Hatcher MJ, Peterson RA, Farnsworth KD and Richardson DM, Advancing impact prediction and hypothesis testing in invasion ecology using a comparative functional response approach. Biol Invasions 16: 735-753 (2014).

35 R Core Team, R: A language and environment for statistical computing. R Foundation for Statistical Computing, Vienna, Austria (2016). URL https://www.R-project.org/. 36 Lenth R, emmeans: Estimated Marginal Means, aka Least-Squares Means (2018). R package version 1.3.0. https://CRAN.R-project.org/package=emmeans

37 Pritchard DW, Paterson RA, Bovy HC and Barrios-O’Neill D, Frair: an R package for fitting and comparing consumer functional responses. Methods Ecol Evol (online) (2017).

38 Real LA, The kinetics of functional response. Am Nat 111: 289-300 (1977).

39 Rogers D, Random search and insect population models. J Anim Ecol 41: 369-383 (1972).

40 Bolker BM, bbmle: Tools for General Maximum Likelihood Estimation. R Package (2010). Available at www.cran.rproject.org.

41 Nam VS, Yen NT, Duc HM, Tu TC, Thang VT, Le NH, Le Loan L, Huong VTQ, Khanh LHK, Trang HTT, Lam LZY, Kutcher SC, Aaskov JG, Jeffery JAL, Ryan PA and Kay BH, Community-based control of Aedes aegypti by using Mesocyclops in Southern Vietnam. Am J Trop Med Hyg 86: 850-859 (2012). 
42 Barrios-O’Neill D, Dick JTA, Emmerson MC, Ricciardi A, Mac-Isaac HJ, Alexander ME and Bovy JC, Fortune favours the bold: a higher predator reduces the impact of a native but not an invasive intermediate predator. J Anim Ecol 83: 693-701 (2014).

43 Laverty C, Dick JTA, Alexander ME and Lucy FE, Differential ecological impacts of invader and native predatory freshwater amphipods under environmental change are revealed by comparative functional responses. Biol Invasions 17: 1761-1770 (2015).

44 Juliano SA, Ribeiro GS, Maciel-De-Freitas R, Castro MG, Codeco C, Lourenco-de-Oliveira R and Lounibos LP, She's a femme fatale: low-density larval development produces good disease vectors. Mem Inst Oswaldo Cruz 109: 96-103 (2014) .

45 Suchman C and Sullivan B, Vulnerability of the copepod Acartia tonsa to predation by the scyphomedusa Chrysaora quinquecirrha: effect of prey size and behavior. Mar Biol 132: 237 (1998).

46 Yamaguchi A and Kishida O, Antagonistic indirect interactions between large and small conspecific prey via a heterospecific predator. Oikos 125: 271-277 (2016).

47 Williams RJ and Martinez ND, Stabilization of chaotic and nonpermanent food-web dynamics. Eur. Phys. J. B 38: 297-303 (2004).

48 Akre BG and Johnson DM, Switching and sigmoid functional response curves by damselfly naiads with alternative prey available. J Anim Ecol 48: 703-720 (1979).

49 Saha N, Aditya G, Saha GK and Hampton SE, Opportunistic foraging by heteropteran mosquito predators. Aquat. Ecol. 44: 167-176 (2010).

50 Klecka J and Boukal DS, Who eats whom in a pool ? A comparative study of prey selectivity by predatory aquatic insects. PLoS ONE, 7: e37741 (2012).

51 Fischer S, Zanotti G, Castro A, Quiroga L and Vargas DV, Effect of habitat complexity on 
the predation of Buenoa fuscipennis (Heteroptera: notonectidae) on mosquito immature stages and alternative prey. J. Vector Ecol. 38: 215-223 (2013).

52 Saha N, Aditya G and Saha GK, Prey preferences of aquatic insects: potential implications for the regulation of wetland mosquitoes. Med Vet Entomol 28: 1-9 (2014).

53 Woodward G and Warren P, Body size and predatory interactions in freshwaters: scaling from individuals to communities, in Body Size: The Structure and Function of Aquatic Ecosystems, ed. by Hildrew AG, Raffaelli DG and Edmonds-Brown R, Cambridge University Press, New York, pp. 98-117 (2007).

54 Saha N, Aditya G, Bal A and Saha GK, A comparative study of predation of three aquatic heteropteran bugs on Culex quinquefasciatus larvae. Limnology 8:73-80 (2007a).

55 Saha N, Aditya G, Banerjee S and Saha GK, Predation potential of odonates on mosquito larvae: Implications for biological control. Biol Control, 63: 1-8 (2012).

56 Scott MA and Murdoch, WW, Selective predation by the backswimmer, Notonecta. Limnol. Oceanogr. 28: 352-366 (1983).

57 Saha N, Aditya G, Bal A and Saha GK, Comparative studies on functional response of common heteropteran bugs of East Calcutta Wetlands, Kolkata, India. Int Rev Hydrobiol 92: $242-257$ (2007b).

58 Zuharah WF and Lester PJ, The influence of aquatic predators on mosquito abundance in animal drinking troughs in New Zealand. J Vector Ecol 35: 347-353 (2010).

59 Matthews PG and Seymour RS, Haemoglobin as a buoyancy regulator and oxygen supply in the backswimmer (Notonectidae, Anisops). J Exp Biol 211: 3790-3799 (2008).

60 Dalal A and Gupta S, A comparative study of the aquatic insect diversity of two ponds located in Cachar District, Assam, India. Turk J Zool 40: 392-401 (2016). 
61 Vonesh JR and Blaustein L, Predator-induced shifts in mosquito oviposition site selection: a meta-analysis and implications for vector control. Isr J Ecol Evol, 56: 263-279 (2010). 
Table 1. Functional response (FR) types resulting from logistic regression, with first and second order terms of Ansiops breddini and Anisops sardeus against four instars $\left(1^{\text {st }}-4^{\text {th }}\right)$ of Culex quiquefasciatus at three different level of water depth. First order terms are presented for Type II FRs, whilst first and second order terms are presented for Type III FRs.

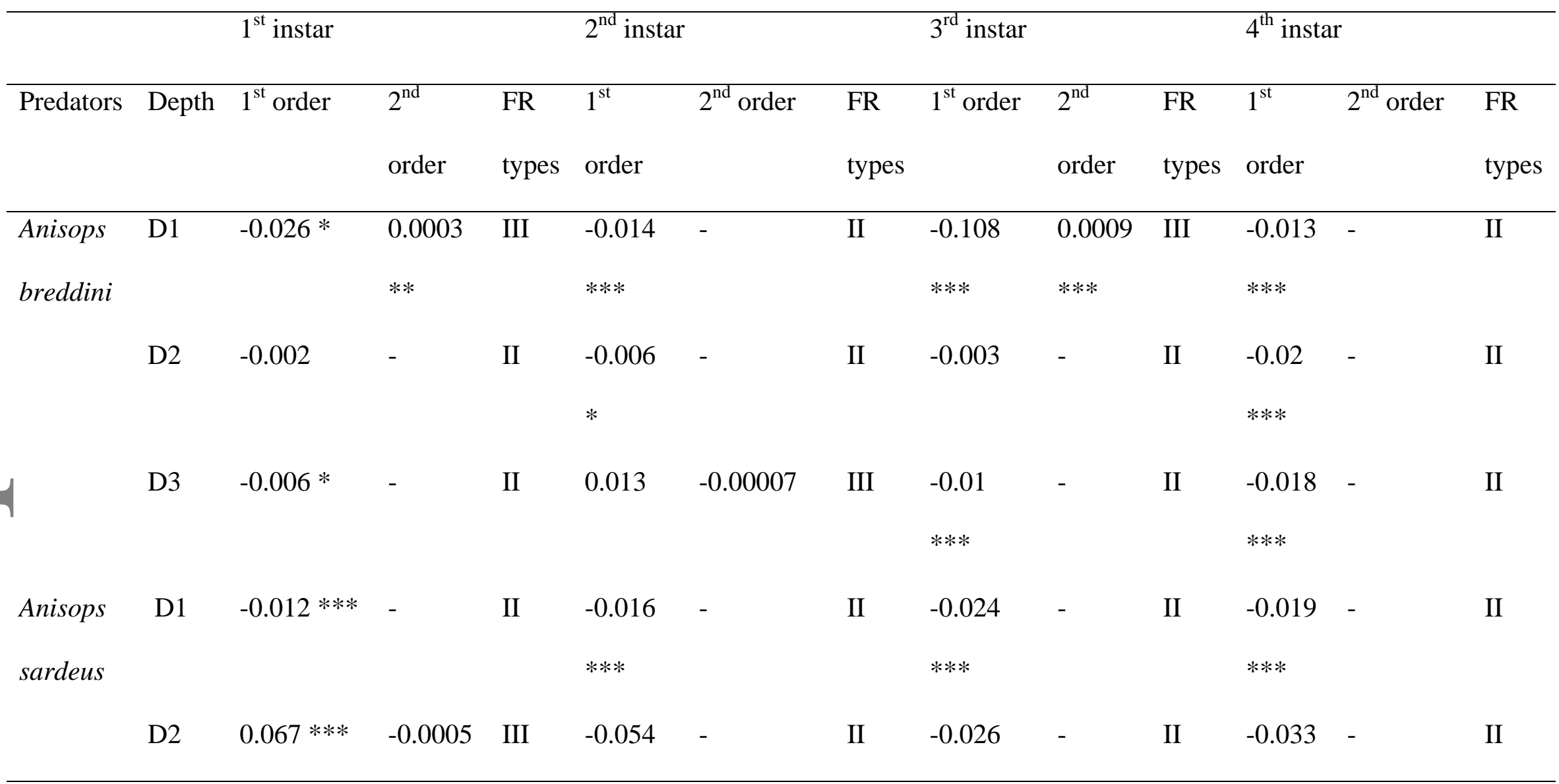




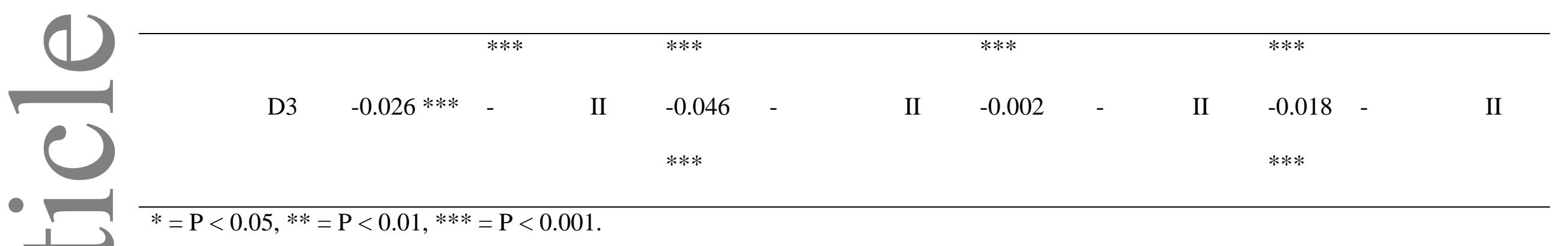

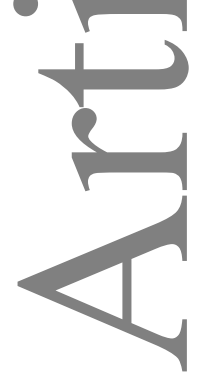

P $<0.05, * *=\mathrm{P}<0.01, * * *=\mathrm{P}<0.001$

This article is protected by copyright. All rights reserved. 
Table 2. Capture rate $(b)$ and handling time $(h)$ parameters of Anisops breddini and Anisops sardeus towards four instars $\left(1^{\text {st }}-4^{\text {th }}\right)$ of Culex quiquefasciatus larvae at three different water depth levels, alongside their significance.

\begin{tabular}{|c|c|c|c|c|c|c|c|c|c|}
\hline & \multirow[b]{2}{*}{$\begin{array}{l}\text { Depth } \\
\text { size }\end{array}$} & \multicolumn{2}{|c|}{$1^{\text {st }}$ instar } & \multicolumn{2}{|c|}{$2^{\text {nd }}$ instar } & \multicolumn{2}{|c|}{$3^{\text {rd }}$ instar } & \multicolumn{2}{|c|}{$4^{\text {th }}$ instar } \\
\hline Predators & & $b$ & $h$ & $b$ & $h$ & $b$ & $h$ & $b$ & $h$ \\
\hline Anisops & D1 & 0.034 & 0.011 & 1.88 & 0.017 & 0.036 & 0.025 & 0.609 & 0.045 \\
\hline \multirow[t]{5}{*}{ breddini } & & $* * *$ & $* * *$ & $* * *$ & $* * *$ & * & $* * *$ & $* * *$ & $* * *$ \\
\hline & D2 & 0.706 & 0.002 & 1.65 & 0.005 & 0.84 & 0.007 & 1.08 & 0.07 \\
\hline & & $* * *$ & & $* * *$ & $* *$ & $* * *$ & & $* * *$ & $* * *$ \\
\hline & D3 & 0.838 & 0.007 & 0.043 & 0.011 & 1.365 & 0.015 & 0.967 & 0.062 \\
\hline & & $* * *$ & $*$ & $* * *$ & $* * *$ & $* * *$ & $* * *$ & $* * *$ & $* * *$ \\
\hline Anisops & D1 & 1.449 & 0.009 & 0.155 & 0.014 & 2.694 & 0.024 & 3.776 & 0.057 \\
\hline \multirow[t]{5}{*}{ sardeus } & & $* * *$ & $* * *$ & $* * *$ & $* * *$ & $* * *$ & $* * *$ & $* *$ & $* * *$ \\
\hline & $\mathrm{D} 2$ & 0.082 & 0.01 & 0.275 & 0.018 & 2.41 & 0.021 & 4.726 & 0.066 \\
\hline & & $* * *$ & $* * *$ & $* * *$ & $* * *$ & $* * *$ & $* * *$ & $* * *$ & $* * *$ \\
\hline & D3 & 2.37 & 0.025 & 0.258 & 0.016 & 0.881 & 0.004 & 5.02 & 0.082 \\
\hline & & $* * *$ & $* * *$ & $* * *$ & $* * *$ & $* * *$ & & $*$ & $* * *$ \\
\hline
\end{tabular}




\section{Figure legends}

Figure 1. Mean raw consumption $( \pm \mathrm{SE}$ ) of Anisops breddini (black coloured bar, a $-\mathrm{d})$ and Anisops sardeus (grey coloured bar, e $-\mathrm{h}$ ) across all four densities towards four prey instar stages $\left(1^{\text {st }}-4^{\text {th }}\right)$ of Culex quinquefasciatus at three increasing water depths (D1 - D3).

Figure 2. Functional responses of Anisops breddini $(\mathrm{a}-\mathrm{d})$ and Anisops sardeus $(\mathrm{e}-\mathrm{h})$ towards four prey instar stages $\left(1^{\text {st }}-4^{\text {th }}\right)$ of Culex quiquefasciatus larvae across low (D1, solid lines), medium (D2, dashed lines) and high (D3, dotted lines) water depths. Bootstrapped $(n=2000)$ 95\% confidence intervals are the shaded areas. Points are raw residuals: D1 (squared points, $\square$ ), D2 (round shaped points, ) and D3 (triangle shaped points, $\triangle$ ).

Figure 3. Capture rates of Anisops breddini (round shaped dots, a - d) and Anisops sardeus (square shaped dots, e $-\mathrm{h}$ ) against four different instar stages $\left(1^{\text {st }}-4^{\text {th }}\right)$ of Culex quiquefasciatus at three water depths (D1, D2, D3). Points are attack rate estimates and bars represent bootstrapped $95 \%$ CIs $(n=2000)$.

Figure 4. Handling times of Anisops breddini (round shapes, a - d) and Anisops sardeus (square shapes, e $-\mathrm{h}$ ) against four different instar stages $\left(1^{\text {st }}-4^{\text {th }}\right)$ of Culex quiquefasciatus at three water depths (D1, D2, D3). Points are handling time estimates and bars represent bootstrapped 95\% CIs $(n=2000)$. 


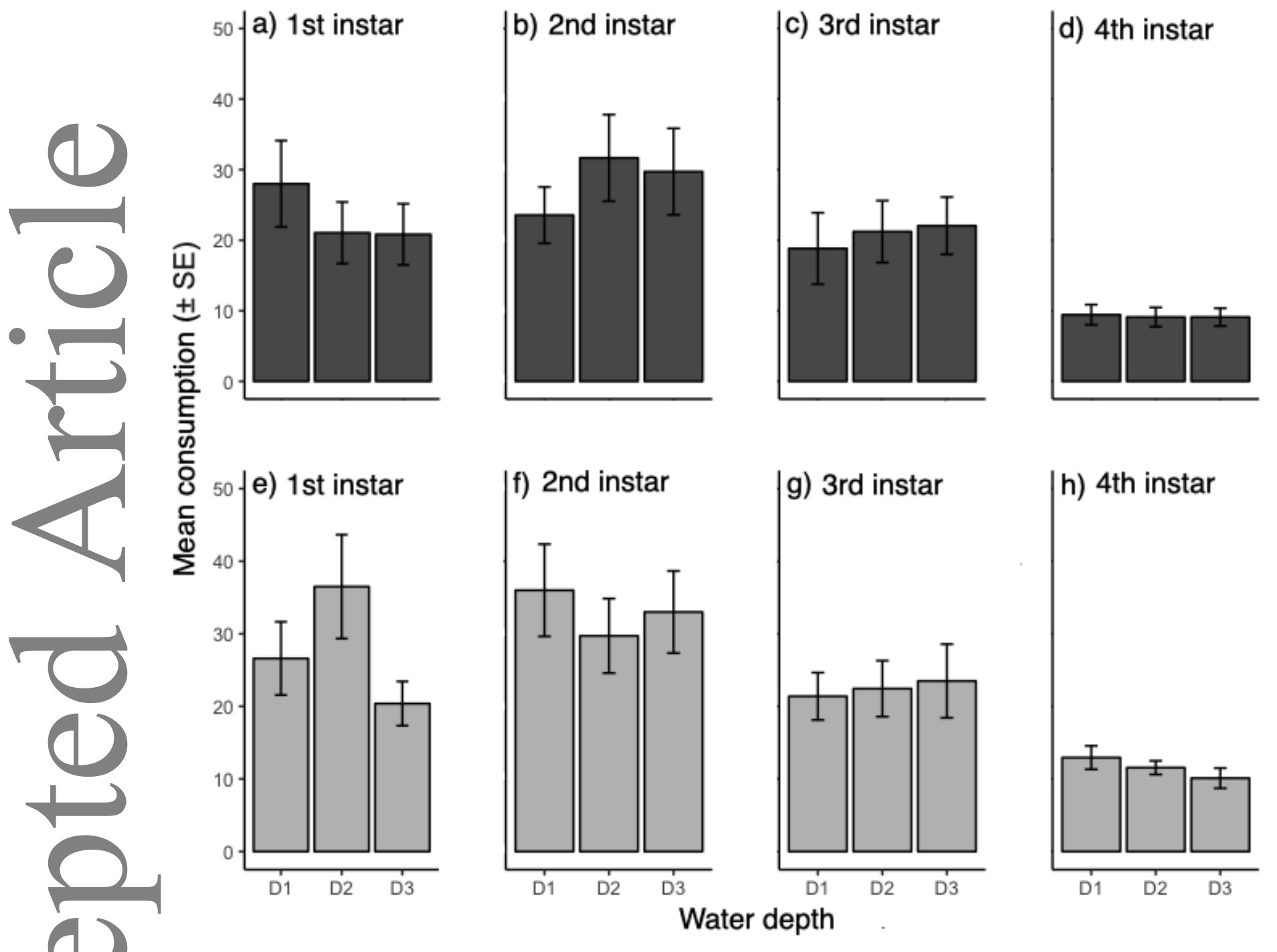

Figure 1. Mean raw consumption ( \pm SE) of Anisops breddini (black coloured bar, a $-\mathrm{d}$ ) and Anisops sardeus (grey coloured bar, e - h) across all prey densities towards four prey instar stages $\left(1^{\text {st }}-4^{\text {th }}\right)$ of Culex quinquefasciatus at three increasing water depths (D1 - D3). 


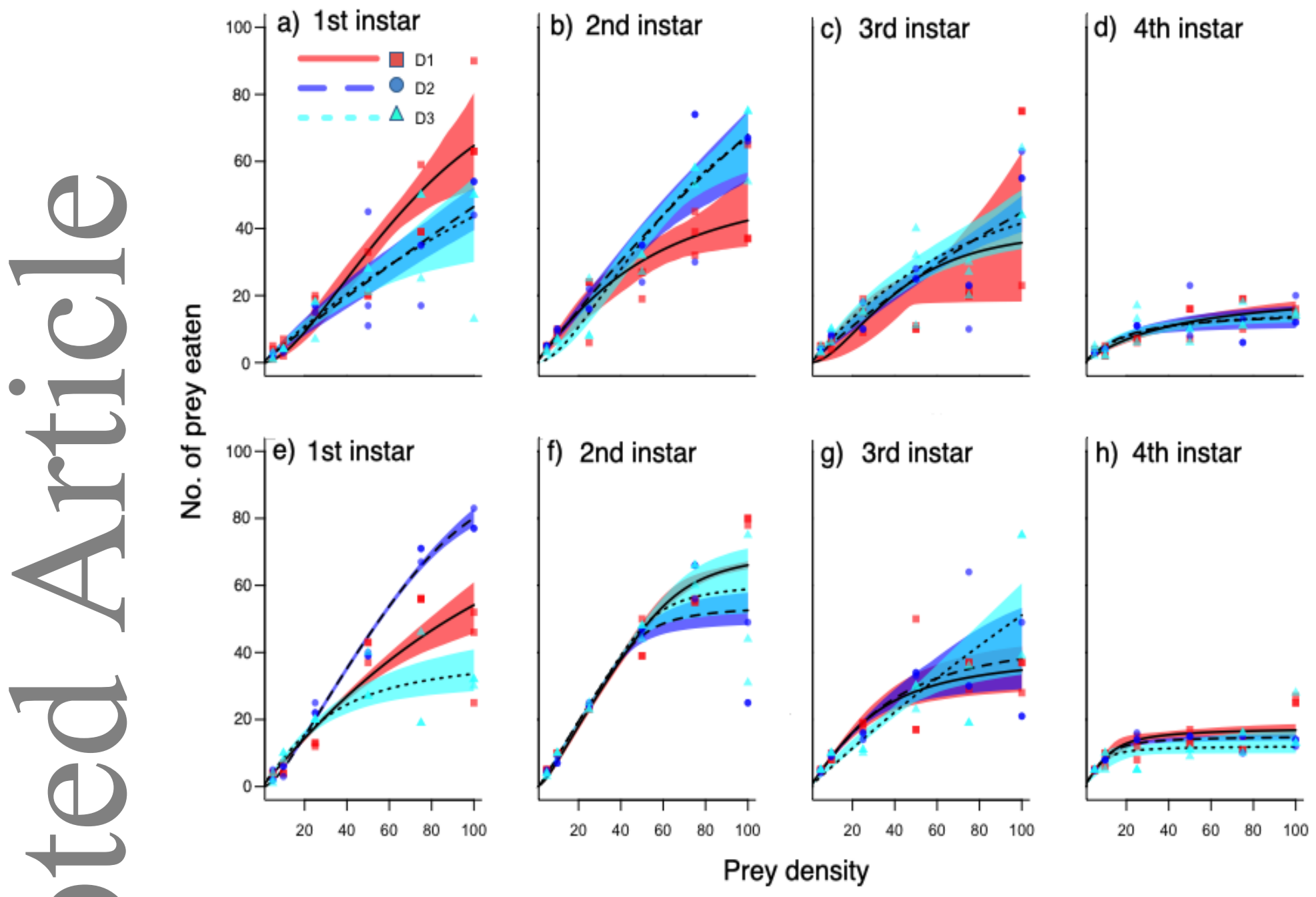

Figure 2. Functional responses of Anisops breddini $(\mathrm{a}-\mathrm{d})$ and Anisops sardeus $(\mathrm{e}-\mathrm{h})$ towards four prey instar stages $\left(1^{\mathrm{st}}-4^{\mathrm{th}}\right)$ of Culex quiquefasciatus larvae across low (D1, solid lines), medium (D2, dashed lines) and high (D3, dotted lines) water depths. Bootstrapped $(n=2000)$ 95\% confidence intervals are the shaded areas. Points are raw residuals: D1 (squared points, $\square$ ), D2 (round shaped points, ) and D3 (triangle shaped points, $\triangle$ ). 


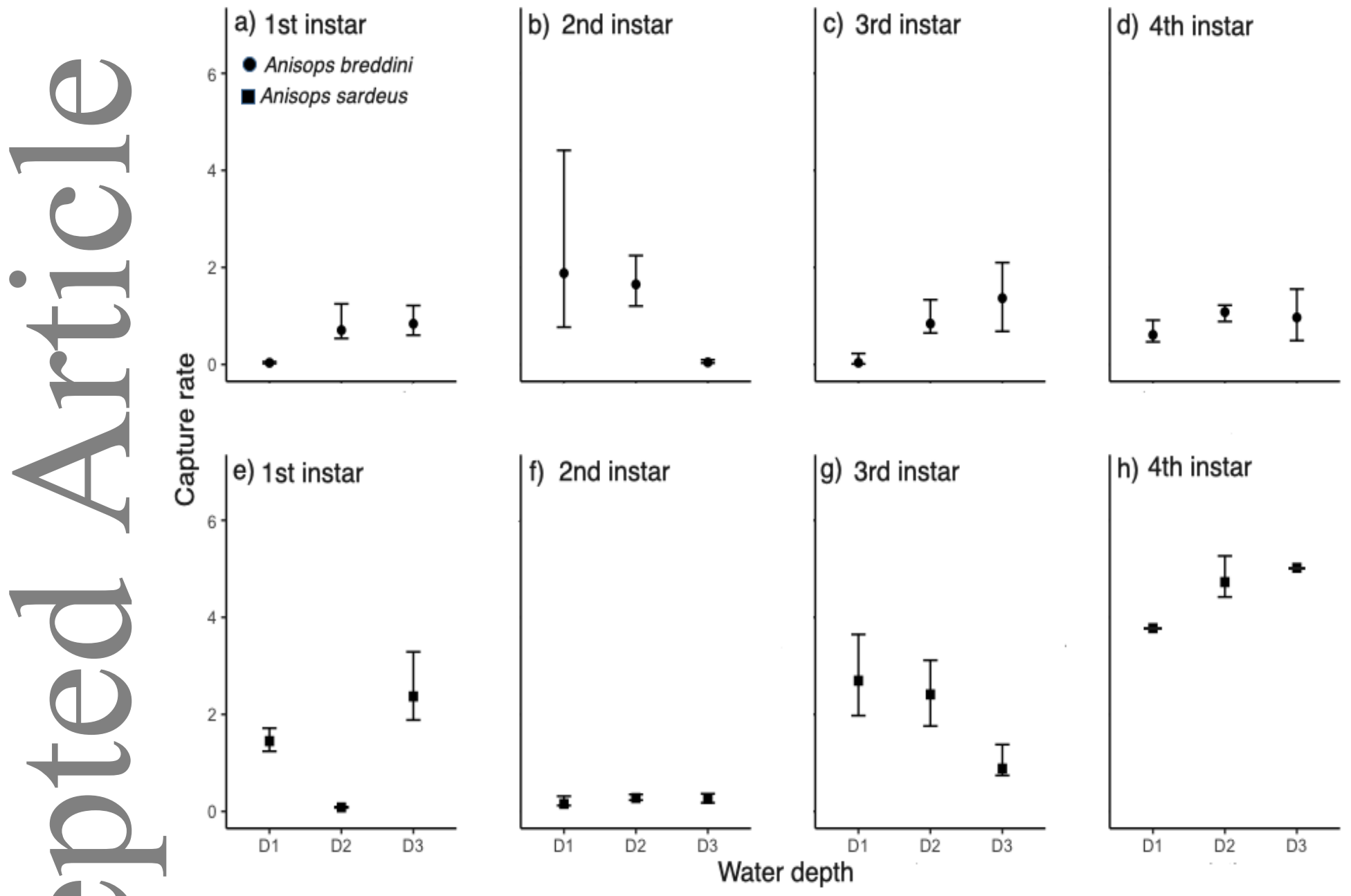

Figure 3. Capture rates of Anisops breddini (round shaped dots, a - d) and Anisops sardeus (square shaped dots, e $-\mathrm{h}$ ) against four different instar stages $\left(1^{\text {st }}-4^{\text {th }}\right)$ of Culex quiquefasciatus at three water depths (D1, D2, D3). Points are attack rate estimates and bars represent bootstrapped 95\% CIs $(n=2000)$. 


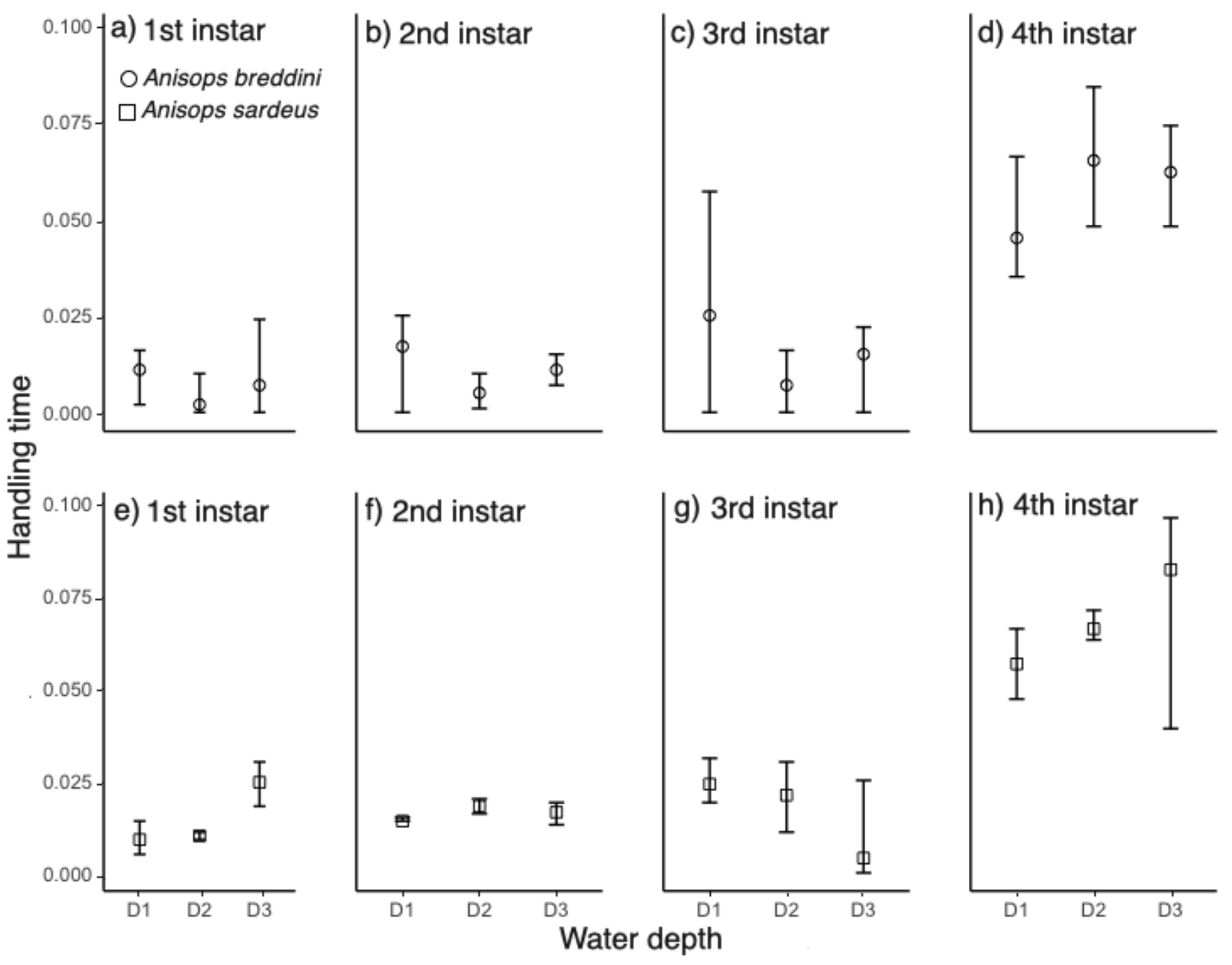

Figure 4. Handling times of Anisops breddini (round shapes, a - d) and Anisops sardeus (square shapes, e - h) against four different instar stages $\left(1^{\text {st }}-4^{\text {th }}\right)$ of Culex quiquefasciatus at three water depths (D1, D2, D3). Points are handling time estimates and bars represent bootstrapped 95\% CIs $(n=2000)$. 